\title{
Does the MRCGP examination discriminate against Asian doctors?
}

\author{
Richard Wakeford, Azhar Farooqi, Aly Rashid, Lesley Southgate
}

Cambridge University School of Clinical Medicine, Clinical School Offices, Addenbrooke's Hospital, Cambridge CB2 $2 Q Q$

Richard Wakeford, educational adviser

\section{Uppingham Road Health Centre, Leicester LE5 4BP Azhar Farooqi, general} practitioner

\section{Health Centre,}

Countesthorpe, Leicester LE8 30

Aly Rashid, general

practitioner

Department of General Practice and Primary Care, Medical Colleges of St Bartholomew's and Royal London Hospitals, London EC1M 6BQ

Lesley Southgate, professor

Correspondence to:

Dr Farooqi.

\author{
Abstract \\ Objective-To ascertain whether the membership \\ examination for the Royal College of General \\ Practitioners (MRCGP) discriminates against \\ doctors of Indian subcontinent ethnic origin ("Asian \\ doctors"). \\ Design-Retrospective analysis of data from \\ five administrations of the MRCGP examination \\ (December 1988-December 1990). \\ Setting-United Kingdom national examination \\ body.
}

Subjects -3686 doctors taking the examination for the first time, 244 of whom were classified as Asian, the remainder as non-Asian.

Main outcome measures-Comparison of performance in each of the written and oral components of the examination between Asian doctors, identified by their names and classified into subgroups by countries of birth and primary medical training from data provided at registration, and non-Asian doctors.

Results - On written components of the examination (multiple choice paper mean score Asians versus non-Asians $42.3 v \mathbf{4 8 . 6}$, modified essay paper $40.9 v 48.9$, practice topic/critical reading paper 41.5 $v 48.7$, all $\mathrm{p}<0.001$ by $t$ testing). But analysis by countries of birth and primary training showed that these differences were due largely to poor performance by certain groups of Asian doctors, especially those born and trained in the Indian subcontinent or elsewhere outside the United Kingdom. Asian doctors born and trained in the United Kingdom and those born in Africa or the West Indies and trained in the United Kingdom performed similarly to the nonAsian doctors.

Conclusions - The examination does not systematically discriminate against Asian doctors, but the poor performance of the two subgroups of Asians is cause for serious concern and requires investigation.

\section{Introduction}

The membership examination of the Royal College of General Practitioners (MRCGP) is designed to assess the competence of general practitioner trainees in the United Kingdom at the end of their specialist training. It is taken by about $80 \%$ of them (examination division, Royal College of General Practitioners, personal communication). Passing this examination is the method of entry to the college.

In 1989 the Leicester faculty of the college expressed its concern regarding poor representation of general practitioners whose ethnic origin was from the Indian subcontinent within the membership of the college (Leicester Faculty Board discussion paper for Royal College of General Practitioners council meeting).

We refer to these doctors as "Asian" for brevity. Nationally the proportion of general practitioners from ethnic minorities is about $20 \%$; the vast majority of these practitioners are of Asian ethnic origin. ${ }^{1}$ The faculty's perception was that the membership of the college did not reflect this (no data exist on ethnic origin of members). As all royal colleges have in the past been accused of not passing young Asian doctors in their examinations at the same rate as their white counterparts, ${ }^{2}$ a particular concern was the college's examination for membership-whether it could be discriminating against Asian candidates.

The college accordingly convened a working group with a brief to ascertain any differences in performance in the examination between Asian and non-Asian doctors. This paper presents the group's results.

\section{Methods}

Ethnic origin can be identified from a mixed population by names. ${ }^{34}$ The reliability of this procedure has been shown to be $85 \%$ when surnames alone are used, when the judgments were made by a white British subject. ${ }^{5}$ We used this method, but the judges were ethnic Asians (AF and AR), knowledgeable about names from the Indian subcontinent, and they had access to both forenames and surnames. The Indian subcontinent was defined by us as comprising Bangladesh, India, Pakistan, and Sri Lanka.

To obtain appropriately large numbers for statistical testing the names of the candidates from five diets of the college examination (December 1988-December 1990) were examined. To avoid bias only those taking the examination for the first time were included; Asian candidates were identified as above. All other candidates were grouped as non-Asians. The Asian candidates were divided, from information provided on their registration forms, to provide five subsidiary groups for comparison on the basis of country of birth and country of primary medical training. The six groups were thus: group 1, non-Asians; group 2, Asians born and trained in the United Kingdom; group 3, Asians born in the Indian subcontinent and trained in the United Kingdom; group 4, Asians born in Africa or the West Indies and trained in the United Kingdom; group 5, Asians born in the Indian subcontinent and trained overseas (not the United Kingdom, generally Indian subcontinent); and group 6, Asians who could not be classified as above ("others"; most were born abroad, many were trained in the Middle East or eastern Europe).

The examination comprises three written papers and two oral tests. The written papers include a multiple choice question paper, a modified essay question paper, and (until 1990) an essay paper called the practice topic question paper. In 1990 the essay paper was replaced by a "critical reading question paper" as a result of a major review of the examination. ${ }^{6}$ For our purposes marks from these two alternative papers were aggregated.

At every component of the examination, the marks on each of the written papers are standardised to a mean of 47.5 and standard deviation of 10 . The three marks are then summated, and the lowest scoring $15 \%$ of candidates are deemed to have failed. The remainder 
proceed to the orals. Each oral was (during the time of the study) marked out of 10 , and the score expressed as a percentage. (Their two marks were then added to those for the written papers to produce a total, which needed to be at least $50 \%$ for the candidate to achieve a pass.)

Mean scores of groups 2 to 6 as a whole (all Asians) were compared with those of group 1 (non-Asians) with separate variance $t$ tests for marks for multiple choice question, modified essay question, practice topic question or critical reading question respectively and marks on each of the two orals. Analysis of variance was then performed with respect to each of the five component scores between the six groups. Post hoc comparisons between all groups were then made with Tukey's honestly significant difference statistic. The significance level was set at a deliberately liberal $0.05 \%$. All statistics were computed with SPSSPC+, version 4.0.

\section{Results}

Of 3686 candidates, $244(6.6 \%)$ were deemed to be of Asian origin. The table shows the number in each group and their mean scores and standard deviations for each component test. On the written components of the examination Asian candidates as a whole performed significantly and substantially worse than others (table). On the orals differences were much smaller and not significant.

Analysis by countries of birth and training showed a more complicated pattern, though one which was similar between the written papers. Analysis of variance showed significant differences between groups (table). For each of the written papers the Tukey statistic showed that doctors in groups 5 and 6 (Asians born in the Indian subcontinent, not trained in the United Kingdom and "other" Asians) each performed significantly worse than any of the other groups. Additionally, on the multiple choice and the modified essay question papers doctors in group 3 (Asians born in the Indian subcontinent, trained in the United Kingdom) performed significantly worse than those in group 1 (non-Asians).

In Oral 1 doctors in group 6 ("other" Asians) performed significantly worse than those in groups 1 , 2, and 4 (non-Asians; Asians born and trained in the United Kingdom; and Asians born in Africa or the West Indies, trained in the United Kingdom). In Oral 2 no two groups were significantly different.

The numbers of candidates taking the oral examination are lower than those taking the written tests because the bottom $15 \%$ are excluded from the oral. The table shows the numbers in each group proceeding to the oral examination: as percentages these were: group $1,89 \cdot 6 \%$; groups $2-6,59 \cdot 4 \%$; group $2,90 \cdot 5 \%$; group $3,80 \cdot 0 \%$; group $4,91 \cdot 5 \%$; group $5,26.3 \%$; and group $6,37 \cdot 5 \%$.

\section{Discussion}

These results show that the MRCGP examination is not systematically discriminating against Asian ethnicity. Non-Asian doctors, Asian doctors born and trained in the United Kingdom, and doctors born in Africa or the West Indies and trained in the United Kingdom who sat the examination for the first time performed equally well. However, certain other subgroups (notably Asian doctors born and trained mainly in the Indian subcontinent and "other" Asian doctors) performed very badly. This is worrying as many have received vocational training in the United Kingdom, and some are in practice as general practitioners. Although the identification of Asians by means of names is not completely precise, this source of error seems unlikely to account for these substantial differences.

One suggested explanation for the poor examination performance of some Asians is that the questions posed in the modified essay question paper do not reflect the harsh realities of inner city practice, experienced by many doctors of Indian subcontinent ethnic origin, and as a result such doctors perform poorly in it. The data offer little support to such a view as poor performance in the modified essay question paper is matched by poor performance in the other two written papers. (And in fact, questions in the modified essay question paper based on inner city practice and the problems brought by patients of ethnic minorities are deliberately commonplace.)

We think a more plausible explanation is that the college examination is measuring the effects of poor training or training which is not congruent with general practice in the United Kingdom. There is evidence that Asian doctors often train in the worst rather than the best training practices and usually have to construct their own vocational training schemes. Candidates born in the Indian subcontinent and trained in the United Kingdom may also be in practices in inner city areas with high workload and little

Comparison of examination scores of Asian and non-Asian applicants

Mean $\quad$ SD $\begin{gathered}\text { No proceeding } \\ \text { to oral } \\ \text { examinations }\end{gathered}$

\begin{tabular}{lcrr}
\hline \multicolumn{4}{c}{ Multiple choice question paper } \\
Group 1 (non-Asians) & $48 \cdot 6$ & $9 \cdot 4$ & 3442 \\
Groups 2-6 (all Asians) & $42 \cdot 3$ & $11 \cdot 3$ & 244 \\
Group 2 & $51 \cdot 1$ & $9 \cdot 8$ & 21 \\
Group 3 & $44 \cdot 4$ & $10 \cdot 7$ & 60 \\
Group 4 & $47 \cdot 1$ & $9 \cdot 9$ & 47 \\
Group 5 & $37 \cdot 4$ & $10 \cdot 8$ & 76 \\
Group 6 & $37 \cdot 9$ & $9 \cdot 0$ & 40
\end{tabular}

$t$ Test: $t=8 \cdot 58, \mathrm{df}=267 \cdot 5, \mathrm{p}<0.001^{\star}$

Analysis of variance: $F$ ratio $32.96, \mathrm{df}=5, \mathrm{p}<0.001 \dagger$

$\begin{array}{lcr} & \text { Modified essay question paper } \\ \text { Group 1 (non-Asians) } & 48.9 & 9.3 \\ \text { Groups 2-6 (all Asians) } & 40.9 & 11.6 \\ \text { Group 2 } & 47.7 & 7.8 \\ \text { Group 3 } & 44.6 & 9.5 \\ \text { Group 4 } & 49.0 & 8.8 \\ \text { Group 5 } & 33.6 & 10.0 \\ \text { Group 6 } & 35.9 & 11.5\end{array}$

3442
244
21
60
47
76
40

$t$ Test: $t=10 \cdot 56, \mathrm{df}=265 \cdot 8, \mathrm{p}<0.001^{\star}$

Analysis of variance: $F$ ratio $55 \cdot 80, \mathrm{df}=5, \mathrm{p}<0 \cdot 001 \dagger$

Practice topic/critical reading question paper

Group 1 (non-Asians)

Group 1 (non-Asians)

Group 2

Group 3

Group 4

Group

Group 6

$\begin{array}{rr}48 \cdot 7 & 9 \cdot 3 \\ 41 \cdot 5 & 11 \cdot 8\end{array}$

$50.6 \quad 7 \cdot 1$

$45 \cdot 4$

$36 \cdot 2$

$t$ Test: $t=9 \cdot 41, \mathrm{df}=264 \cdot 8, \mathrm{p}<0.001^{\star}$

Analysis of variance: $F$ ratio $50.51, \mathrm{df}=5, \mathrm{p}<0.001 \dagger$

$\begin{array}{lrrr} & \text { Oral l } & & \\ \text { Group 1 (non-Asians) } & 64 \cdot 2 & 10 \cdot 7 & 3084 \\ \text { Groups 2-6 (all Asians) } & 62 \cdot 6 & 11 \cdot 7 & 145 \\ \text { Group 2 } & 66 \cdot 6 & 9 \cdot 1 & 19 \\ \text { Group 3 } & 59 \cdot 9 & 12 \cdot 7 & 48 \\ \text { Group 4 } & 67 \cdot 1 & 10 \cdot 1 & 43 \\ \text { Group 5 } & 61 \cdot 5 & 11 \cdot 7 & 20 \\ \text { Group 6 } & 55 \cdot 0 & 9 \cdot 6 & 15\end{array}$

$t$ Test: $t=1 \cdot 58, \mathrm{df}=155 \cdot 6, \mathrm{p}=0 \cdot 116^{\star}$

Analysis of variance: $F$ ratio $4 \cdot 79, \mathrm{df}=5, \mathrm{p}<0.001 \dagger$

$\begin{array}{lrrr} & \text { Oral 2 } & & \\ \text { Group 1 (non-Asians) } & 65 \cdot 5 & 11 \cdot 0 & 3084 \\ \text { Groups 2-6 (all Asians) } & 63 \cdot 6 & 11 \cdot 9 & 145 \\ \text { Group 2 } & 68 \cdot 1 & 11 \cdot 4 & 19 \\ \text { Group 3 } & 62 \cdot 5 & 12 \cdot 2 & 48 \\ \text { Group 4 } & 65 \cdot 9 & 9 \cdot 8 & 43 \\ \text { Group 5 } & 61 \cdot 5 & 12 \cdot 8 & 20 \\ \text { Group 6 } & 58 \cdot 0 & 14 \cdot 2 & 15\end{array}$

$t$ Test: $t=1 \cdot 79, \mathrm{df}=155 \cdot 7, \mathrm{p}=0.076^{\star}$

Analysis of variance: $F$ ratio $2 \cdot 80, \mathrm{df}=5, \mathrm{p}=0.015 \dagger$

*Group 1 versus groups 2-6.

tGroups 1-6. 
opportunity for protected study time. An unknown proportion of the poorly performing groups will have undertaken their postgraduate training abroad. And for some, English may well not be the first language or, for the "other" Asians, the language of primary medical training. Experience in Canada suggests that language pervades tests whose primary intent is to assess medical matters. ${ }^{8}$ So this may also be seen as a likely explanation for the poor performance of such of the "other" Asian candidates who reach Oral 1.

We are encouraged by these results in so far as they suggest no general discrimination in the MRCGP examination on the basis of ethnic origin. But we wish to understand why postgraduate medical training in the United Kingdom may be systematically failing some groups of Asian candidates. We therefore plan to investigate the problem of poor performance further, case by case.

The authors were convened as a working group of the Examination Board of the Royal College of General Practitioners (LS is the convener of the panel of examiners and RW is consultant). We thank the board for its encouragement to publish this paper and Tom Dastur, examination administrator, for his help.

1 Department of Health and Social Security, Statistics and Research Division. Census survey of medical manpower in the United Kingdom. London: DHSS, 1986.

2 Anwar M. Overseas doctors: experience and expectations. London: Commission for Racial Equality, 1987

3 Donaldson LJ. Health and social status of elderly Asians: a community survey. BMF 1986;293:1079-82.

4 McAvoy BR, Raza R. Asian women: (1) contraceptive knowledge, attitudes and usage; (2) contraceptive services and cervical cytology. Health Trends 1988;20:11-7

5 McManus IC, Maitlis SL, Richards P. Identifying medical school applicants from ethnic minorities. Studies in Higher Education 1990;15:57-73.

6 Lockie C, ed. Examination for membership of the Royal College of General Practitioners $(M R C G P)$. London: Roval College of General Practitioners, 1990. (Occasional paper No 46.)

7 Rashid A. Asian doctors and nurses in the NHS. In: McAvoy BR, Donaldson LJ, eds. Health care for Asians. Oxford: Oxford University Press, 1990:46-56. L de demographic and personal predictors of success on an OSCE-format internship programme entrance examination. In: Proceedings of the twenty Washington, DC: Association of American Medical Colleges, 1988:234-9.
So I started with the past, much of which I had picked up from the old $B M \mathcal{F}$, which mentioned that French medical journals had recorded strong protests against the cruel practice of performing animal experiments in public. Two great names, those of Magendie and Claude Bernard, were mentioned as those who regularly perpetrated such abuse. When I tried to explain their contributions to medicine Sally was not impressed. She nearly gave up her speech when I read her this passage:

Magendie, alas! performed experiments in public, and sadly too often at the College de France. I remember once, amongst other instances, the case of a poor dog the roots of whose spinal nerves he was about to expose. Twice did the dog, all bloody and mutilated, escape from his implacable knife, and twice did I see him put his fore legs around Magendie's neck and lick his face. I confess-laugh Messieurs les Vivisecteurs, if you please - that I could not bear the sight. And again, helas! M. Cl. Bernard performs vivisections in public in his course of physiology.

I argued that these were important pioneers, some of whom had had their statues erected in public places. Sally put forward a flawless counter argument: "It's the dog who deserves recognition, and all medical labs should erect dogs' statues and pay due respect to the animals who lose their lives during experiments." This was the line she intended to take with her audience.

I then pointed to the present debate, explaining the value of animal experiments in fighting cancer, AIDS, and many more diseases. She seemed to agree with such use of animals, but only if they were treated properly. As for the future, Sally was sure that animal experiments would soon be out of date; in her opinion computer models would be far superior tools, and in any case maybe not many animals would be left in another 50 years.

Next day I asked her how her speech had gone. She told me she had lost the motion by one vote. - N H NAQVI, consultant anaesthetist, Bolton General Hospital 